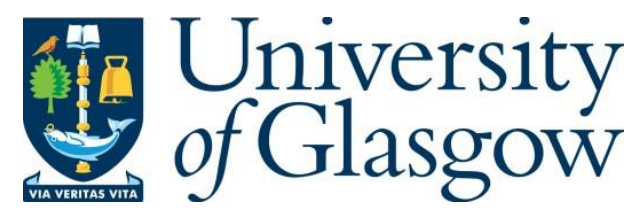

Li, T., Jin, L., Zhang, W., Miras, H. N. and Song, Y.-F. (2018) Robust and environmentally benign solid acid intercalation catalysts for the aminolysis of epoxides. ChemCatChem, 10(20), pp. 4699-4706.

There may be differences between this version and the published version. You are advised to consult the publisher's version if you wish to cite from it.

This is the peer reviewed version of the following article Li, T., Jin, L., Zhang, W., Miras, H. N. and Song, Y.-F. (2018) Robust and environmentally benign solid acid intercalation catalysts for the aminolysis of epoxides. ChemCatChem, 10(20), pp. 4699-4706, which has been published in final form at http://dx.doi.org/10.1002/cctc.201801119. This article may be used for noncommercial purposes in accordance with Wiley Terms and Conditions for SelfArchiving.

$\underline{\text { http://eprints.gla.ac.uk/168039/ }}$

Deposited on: 29 October 2018

Enlighten - Research publications by members of the University of Glasgow http://eprints.gla.ac.uk 


\title{
Robust and environmentally benign solid acid intercalation catalysts for the aminolysis of epoxides
}

\author{
Tengfei Li ${ }^{a \dagger}{ }^{\dagger}$ Lin Jin, ${ }^{a \dagger}$ Wei Zhang, ${ }^{a}$ Haralampos N. Miras ${ }^{\star b}$ and Yu-Fei Song ${ }^{\star a}$
}

\begin{abstract}
The catalytic aminolysis of epoxides can lead to a large number of $\beta$-amino alcohols which are of particular interest in industrial applications. In this paper, we demonstrate for the first time the use of a polyoxometalate $\left[\mathrm{CoW}_{12} \mathrm{O}_{40}\right]^{5-}$ intercalated layered double hydroxides $\left(\mathrm{Zn}_{3} \mathrm{Al}-\mathrm{LDH}\right)$ material as an efficient solid acid catalyst for the catalytic aminolysis of various epoxides under mild and solvent-free conditions. The as-prepared heterogeneous catalyst $\mathrm{Zn}_{3} \mathrm{Al}-\mathrm{CoW}_{12}$ was fully characterized by FT-IR, powder XRD, TG-DTA, BET, XPS, SEM, HR-TEM and $\mathrm{NH}_{3}$-TPD. The catalytic performance of $\mathrm{Zn}_{3} \mathrm{Al}-\mathrm{CoW}_{12}$ for the aminolysis of epoxides revealed excellent yields with high regioselectivity and stereoselectivity. Moreover, the solid acid catalyst can be easily recycled and reused without detectable decrease of its catalytic efficiency.
\end{abstract}

\section{Introduction}

Epoxides are highly significant organic intermediates for the synthesis of various high value-added raw materials in the fine chemical industry. For example, the ethylene oxide ranks one of the top 10 industrially important chemicals produced in the world. ${ }^{[1-3]}$ Its use as industrial feedstock gives rise to the formation of high value intermediates for the production of a wide range of polymers, coatings, anti-freeze formulations and structural materials. The three-membered heterocyclic compounds are structurally strained and provide extremely versatile combination of reactivity and synthetic flexibility. It can easily undergo ring opening reactions in the presence of various nucleophiles (ammonia, amines, alcohols, sulfur-containing compounds etc.), yielding compounds with multiple functional groups. For example, the ring opening of epoxides in the presence of amines is a very important organic reaction for the preparation of $\beta$-amino alcohols, which are mainly used as key intermediates for the manufacturing of various biologically active ingredients, such as $\beta$-blockers, chiral ligands in asymmetric synthesis, anti-obesity, antihypertensive dugs etc. ${ }^{[4-5]}$ Typical synthetic procedures employed for this type of organic transformations involve large excess of the amines at high temperature regimes in the presence of large quantities of

\footnotetext{
[a] T. Li, L. Jin, W. Zhang, Prof. Y.-F. Song*

Beijing Advanced Innovation Center for Soft Matter Science and

Engineering, State Key Laboratory of Chemical Resource

Engineering, Beijing University of Chemical Technology

Beijing 100029 P. R. China

E-mail: songyufei@hotmail.com or songyf@mail.buct.edu.cn

[b] Dr. H. N. Miras*

WestCHEM, School of Chemistry

Glasgow, G12 8QQ (UK)

E-mail: harism@chem.gla.ac.uk

[ $\left.{ }^{\dagger}\right]$ These authors contributed equally to this work.
}

solvents. However, this synthetic approach is far less effective in the case of weak nucleophilic amines and usually suffers from low regio-selectivity. ${ }^{[4-6]}$ To date, a number of catalysts have been applied in the aminolysis of epoxides such as $\mathrm{CoCl}_{2},{ }^{[7]}$ $\mathrm{TaCl}_{5},{ }^{[8]} \mathrm{CeCl}_{3},{ }^{[9]} \mathrm{Sml}_{2},{ }^{[10]} \mathrm{Ti}(\mathrm{O}-i-\mathrm{Pr})_{4},{ }^{[11]}$ metal triflates ${ }^{[12]}$ and basic metal amides. ${ }^{[13]}$ However, utilization of these homogeneous catalytic systems is associated with challenging separation and recycling procedures, which restrict their practical and economically sustainable use in large scale applications. These challenges have attracted the interest of various research groups who focused their research efforts on the development of heterogeneous catalytic systems such as amberlyst-15, ${ }^{[14]}$ Ti-MCM-41, ${ }^{[4]}$ zeolite $Y .{ }^{[15]}$ In a similar manner, these heterogeneous catalysts suffer from several drawbacks such as, long reaction times, poor regio-selectivity and use of large amounts of expensive catalysts. Hence, the development of efficient, recyclable and sustainable heterogeneous catalytic systems for the aminolysis of epoxides and synthesis of $\beta$ amino alcohols is highly important.

Polyoxometalates (POMs) are a class of molecular metal oxide anions that incorporate $\mathrm{V}, \mathrm{Mo}, \mathrm{W}$ or $\mathrm{Nb}$ in their highest oxidation states. ${ }^{[16-18]}$ POMs are very attractive systems due to their fascinating properties such as redox potential, electrontransfer properties and acidity. Their chemical behaviour can be finely tuned by doping the molecular metal oxide framework with appropriate choice of metal ions and heteroatoms leading ultimately to superior catalytic performance in numerous industrial processes. ${ }^{[19-21]}$ In this paper, we evaluated first of al the potential catalytic efficacy of POM species with a Keggin archetype, $\mathrm{K}_{5} \mathrm{CoW}_{12} \mathrm{O}_{40}$ (denoted as $\mathrm{K}_{5} \mathrm{CoW}_{12}$ ), in the catalytic aminolysis of epoxides. Initial studies revealed that the catalytic process proceeds efficiently under mild and solvent-free conditions. However, taking into consideration the associated cost in large-scale applications, it is of fundamental importance to design and fabricate a recyclable, and sustainable heterogeneous catalyst while retain its desirable functionality. Recently, incorporation of the catalytically active anionic POMs into the interlayer region of layered double hydroxides (LDHs), proved to be a very elegant immobilization method, and has been demonstrated to be an effective approach which leads to enhanced dispersity and stability of POM species. Additionally, the LDHs not only act as support but also introduces cooperative effects via multiple interactions developed between the host layers and the guest POM anions. ${ }^{[22-23]}$ The intercalation of POMs into LDHs prevents the POM species from leaching into the reaction mixture while increases the selectivity of the catalytic reaction due to the stabilization of intermediates formed during the reaction in confined spaces. Based on these observations, we designed and fabricated a robust solid acid catalyst by intercalating $\mathrm{CoW}_{12}$ Keggin species into $\mathrm{Zn}_{3} \mathrm{Al}-\mathrm{NO}_{3}$. The resultant heterogeneous $\mathrm{Zn}_{3} \mathrm{Al}-\mathrm{CoW}_{12}$ composite material 
exhibits high efficiency in the catalytic aminolysis of epoxides under mild and solvent-free conditions.

\section{Results and Discussion}

\section{Preparation and characterization of the catalyst}

The employed synthetic procedure for the preparation of $\mathrm{Zn}_{3} \mathrm{Al}-\mathrm{CoW}_{12}$ is shown in Scheme 1. The intercalation of $\mathrm{CoW}_{12}$ anions were carried out following a one-step ion exchange process in the presence of freshly prepared $\mathrm{Zn}_{3} \mathrm{Al}-\mathrm{NO}_{3}$ slurry. The detailed structural characterization of the resultant $\mathrm{Zn}_{3} \mathrm{Al}$ $\mathrm{CoW}_{12}$ was demonstrated using various spectroscopy techniques.
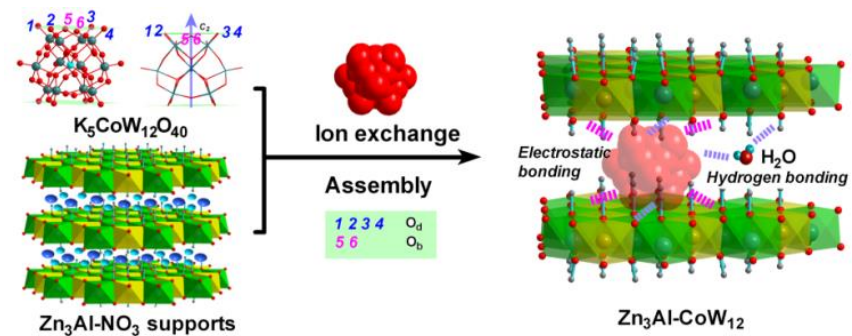

Scheme 1. Schematic representation of the synthetic preparation of the catalyst $\mathrm{Zn}_{3} \mathrm{Al}-\mathrm{CoW}_{12}$.

As shown in Figure 1a, the FT-IR spectrum of $\mathrm{K}_{5} \mathrm{CoW}_{12} \mathrm{O}_{40}$ exhibits characteristic peaks centered at 958, 895, 758 and 438 $\mathrm{cm}^{-1}$, which can be attributed to the vibrations of $\mathrm{W}-\mathrm{O}_{\mathrm{t}}, \mathrm{W}-\mathrm{O}_{\mathrm{c}}-\mathrm{W}$, $\mathrm{W}-\mathrm{O}_{\mathrm{e}} \mathrm{-W}$ and Co-O, (t, terminal; c, corner-sharing; e, edge), respectively. ${ }^{[24]}$ These characteristic $\mathrm{W}-\mathrm{O}$ stretching bands of $\mathrm{CoW}_{12}$ can be clearly observed in the FT-IR spectrum of $\mathrm{Zn}_{3} \mathrm{Al}$ $\mathrm{CoW}_{12}$ composite, where the relevant peaks $941,897,746$ and $435 \mathrm{~cm}^{-1}$, are slightly shifted due to the presence of intermolecular interactions, such as electrostatic and hydrogen bond networks etc. developed between the hydroxyl groups in the brucite-like layers of the LDHs host and the terminal oxygen atoms of $\mathrm{CoW}_{12}$ anions. ${ }^{[25,16]}$ The precursor of $\mathrm{Zn}_{3} \mathrm{Al}-\mathrm{NO}_{3}$ shows a strong stretching band located at $1384 \mathrm{~cm}^{-1}$, which can be assigned to the $\mathrm{N}-\mathrm{O}$ bond vibration of $\mathrm{NO}_{3}{ }^{-}$anions in the interlayer galleries. It should be noted that this band is very weak in the corresponding IR spectrum of $\mathrm{Zn}_{3} \mathrm{Al}-\mathrm{CoW}_{12}$, indicating that the exchange of the $\mathrm{CoW}_{12}$ anions with $\mathrm{NO}_{3}{ }^{-}$is practically quantitative. These results suggest that the $\mathrm{CoW}_{12}$ anions retained their structural integrity during the intercalation into the $\mathrm{Zn}_{3} \mathrm{Al}-\mathrm{NO}_{3}$ gallery.

The powder XRD pattern of various samples are shown in Figure $1 \mathrm{~b}$ and the basal $d_{003}$ spacings are given in Table 1. For the precursor of $\mathrm{Zn}_{3} \mathrm{Al}-\mathrm{NO}_{3}$, it shows a reflection peak centered at $2 \theta=10.02$, which is due to the characteristic reflection of 003 basal plane and corresponds to the spacing value of $d_{003}=0.883$ $\mathrm{nm}$. It should be noted that after intercalation of the $\mathrm{CoW}_{12}$ clusters into $\mathrm{Zn}_{3} \mathrm{Al}-\mathrm{NO}_{3}$, an obvious shift of the 003 reflection (centered at $2 \theta=6.15$ ) to lower angles can be observed. These changes correspond to a basal spacing value of $d_{003}=1.44 \mathrm{~nm}$, indicating an expansion of the interlayer region due to the intercalation of the $\mathrm{CoW}_{12}$ in $\mathrm{Zn}_{3} \mathrm{Al}-\mathrm{CoW}_{12}$. The height of the interlayer gallery $(0.96 \mathrm{~nm})$ is calculated by subtracting the thickness of the host layer $(0.48 \mathrm{~nm})$ from the value of the $d_{003}$ spacing $(1.44 \mathrm{~nm})$ of the $\mathrm{Zn}_{3} \mathrm{Al}-\mathrm{CoW}_{12}$ composite and is in good agreement with the dimension of $\mathrm{CoW}_{12}$ cluster. As shown in Scheme $1, \mathrm{CoW}_{12}$ anions intercalated with their $C_{2}$ axis aligned vertical to the host layer in the interlayer region of the $\mathrm{Zn}_{3} \mathrm{Al}$ LDHs.
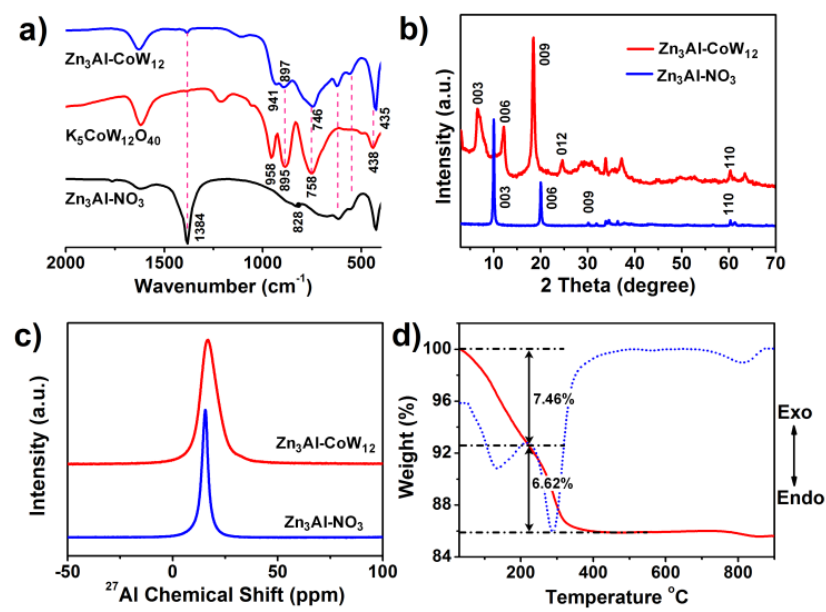

Figure 1. a) FT-IR spectra of $\mathrm{Zn}_{3} \mathrm{Al}-\mathrm{LDH}, \mathrm{K}_{5} \mathrm{CoW}_{12} \mathrm{O}_{40}$ and $\mathrm{Zn}_{3} \mathrm{Al}-\mathrm{CoW}_{12}$; b) The powder XRD patterns of $\mathrm{Zn}_{3} \mathrm{Al}-\mathrm{NO}_{3}$ and $\mathrm{Zn}_{3} \mathrm{Al}-\mathrm{CoW}{ }_{12}$; (inset) representation of $\mathrm{Zn}_{3} \mathrm{Al}-\mathrm{CoW}{ }_{12}$; c) ${ }^{27} \mathrm{Al}$ MAS NMR spectra of $\mathrm{Zn}_{3} \mathrm{Al}-\mathrm{NO}_{3}$ and $\mathrm{Zn}_{3} \mathrm{Al}-\mathrm{CoW}_{12}$; d) TG-DTA profile of $\mathrm{Zn}_{3} \mathrm{Al}-\mathrm{CoW}_{12}$.

In an effort to improve our understanding about the intercalation process, solid state ${ }^{27} \mathrm{Al}$ MAS NMR was used to evaluate the changes in the brucite-like layers during synthesis. It is well established that in terms of the LDHs compounds, the $\mathrm{Al}^{3+}$ ions in the host brucite-like layers adopt an octahedral geometry $\left(\mathrm{AlO}_{6}\right) .{ }^{[26,27]}$ As shown in Figure $1 \mathrm{c}, \mathrm{Zn}_{3} \mathrm{Al}-\mathrm{NO}_{3}$ exhibits a strong and sharp single resonance centered at $\delta=15 \mathrm{ppm}$, indicating the presence of octahedral $\mathrm{Al}^{3+}$ centers in the brucitelike layers. ${ }^{[28,16]}$ After intercalation of the $\mathrm{CoW}_{12}$ clusters, a relative broad ${ }^{27} \mathrm{Al}$ MAS NMR signal is located at almost the same position as the relevant one attributed to the $\mathrm{Zn}_{3} \mathrm{Al}-\mathrm{NO}_{3}$ without detection of resonance signals from tetrahedral $\mathrm{Al}$ centers. This observation indicates that the ZnAl-type brucitelike layers retain their structural integrity during the ion exchange of the interlayer $\mathrm{NO}_{3}{ }^{-}$anions with the $\mathrm{CoW}_{12} \mathrm{POM}$ species.

TG-DTA of $\mathrm{Zn}_{3} \mathrm{Al}-\mathrm{CoW}_{12}$ exhibits two overlapping weightlosses upon increase of the temperature from 30 to $900{ }^{\circ} \mathrm{C}$. In the first stage, the weight loss of $7.46 \%$ between 30 and $225{ }^{\circ} \mathrm{C}$ is due to the removal of water molecules (calcd. $0.89 \mathrm{H}_{2} \mathrm{O}$ per $\mathrm{Zn}_{3} \mathrm{Al}-\mathrm{CoW}_{12}$ ). The second weight loss step of $6.22 \%$ in the range of $225-450{ }^{\circ} \mathrm{C}$ can be attributed to the removal of additional water content formed during the dehydration of the $\mathrm{LDH}$ layers upon heating. In contrast, the TG-DTA of the CoW12 species presented in Figure S1, shows a weight loss of $7.52 \%$ corresponding to the removal of the co-crystallized solvent content and subsequent loss of structural integrity of the POM species at higher temperatures. The molecular formula of $\mathrm{Zn}_{3} \mathrm{Al}$ CoW 12 can be determined as $\mathrm{Zn}_{0.64} \mathrm{Al}_{0.28}(\mathrm{OH})_{1.92}\left(\mathrm{CoW}_{12} \mathrm{O}_{40}\right)_{0.04}$ 
$.0 .89 \mathrm{H}_{2} \mathrm{O}$ (the $\mathrm{CoW}_{12}$ loading, found to be $193.78 \mu \mathrm{mol} / \mathrm{g}$, Co $=$ 1.33 wt. $\%, W=42.57$ wt. $\%$ ) by taking into consideration the TGA and ICP analysis data (Table 1).

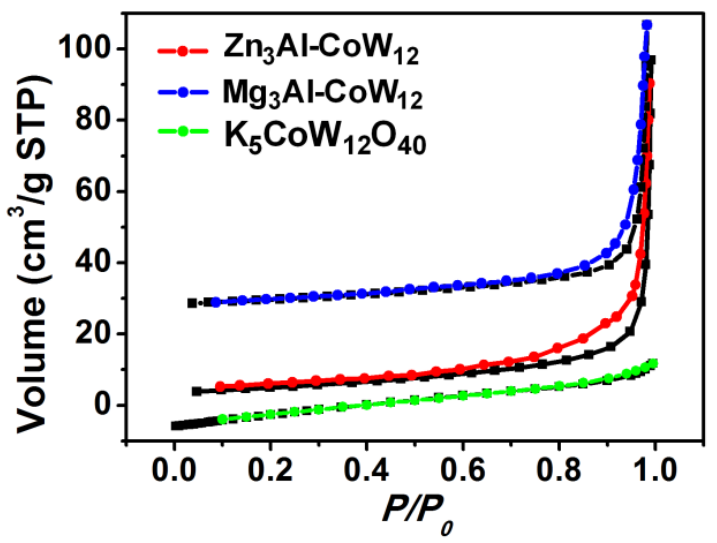

Figure 2. The $\mathrm{N}_{2}$ adsorption/desorption isotherms of $\mathrm{Mg}_{3} \mathrm{Al}-\mathrm{CoW}_{12}$ and $\mathrm{Zn}_{3} \mathrm{Al}-$ $\mathrm{CoW}_{12}$.
As shown in Figure 2, the $\mathrm{N}_{2}$ sorption isotherm of $\mathrm{Zn}_{3} \mathrm{Al}-\mathrm{CoW}_{12}$ composite exhibits the classical type-IV with a $\mathrm{H} 3$ type hysteresis loops, giving a steep increase at a relative pressure of $0.7<P / P_{0}<1$, indicating the presence of slit-like mesoporous structure. Similar isotherms are observed in the case of $\mathrm{Mg}_{3} \mathrm{Al}-$ $\mathrm{CoW}_{12}$ sample. The Barrett-Joyner-Halenda $(\mathrm{BJH})$ pore size distribution curves in Figure S2 give the most probable pore sizes centered at 3.86 and $3.82 \mathrm{~nm}$ for $\mathrm{Zn}_{3} \mathrm{Al}-\mathrm{CoW}_{12}$ and $\mathrm{Mg}_{3} \mathrm{Al}-$ $\mathrm{CoW}_{12}$, respectively. In contrast, the $\mathrm{N}_{2}$ sorption experiment conducted for the $\mathrm{K}_{5} \mathrm{CoW}_{12} \mathrm{O}_{40}$ cluster under identical conditions revealed a non-porous solid. Table 1 also summarizes the textural and chemical properties of various samples. The results indicate that the $\mathrm{Zn}_{3} \mathrm{Al}-\mathrm{CoW}_{12}$ composite exhibits a moderate BET surface area of $33.44 \mathrm{~m}^{2} \cdot \mathrm{g}^{-1}$ with a microporous volume of $0.007 \mathrm{~cm}^{3} \cdot \mathrm{g}^{-1}$ and total pore volume of $0.110 \mathrm{~cm}^{3} \cdot \mathrm{g}^{-1}$, in agreement to our previous observations. ${ }^{[22]}$ The low BET surface area of $13.51 \mathrm{~m}^{2} \cdot \mathrm{g}^{-1}$ obtained in the case of $\mathrm{K}_{5} \mathrm{CoW}_{12} \mathrm{O}_{40}$ is consistent with the low surface areas for common inorganic POM salts. As a result, we obtain two intercalated catalysts which exhibit mesoporosity and moderate BET surface areas.

Table 1. Chemical composition and physical properties of different $\mathrm{LDH}-\mathrm{NO}_{3}$ supports and LDH-POM catalyst.

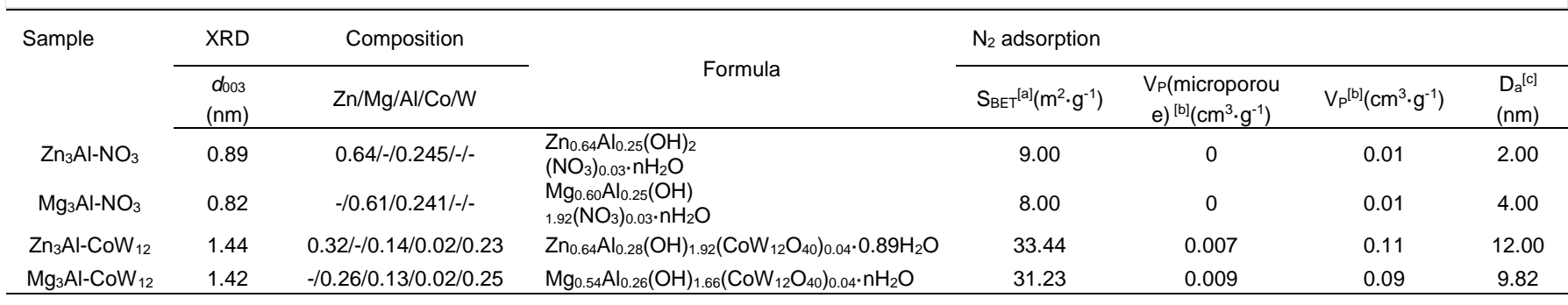

[a] $\mathrm{S}_{\mathrm{BET}}$ : specific surface area calculated by the Multi-point Brunauer-Emmett-Teller $(\mathrm{BET})$ method in the relative adsorption pressure $\left(P / P_{0}\right)$. [b] $\mathrm{V}_{\mathrm{P}}, t-\mathrm{Plot}$ micropore volume. [c] $V_{P}$, total pore volume. [d] $D_{a}$, Pore diameter obtained from the desorption isotherm by the Barrett-Joyner-Halenda (BJH) method.
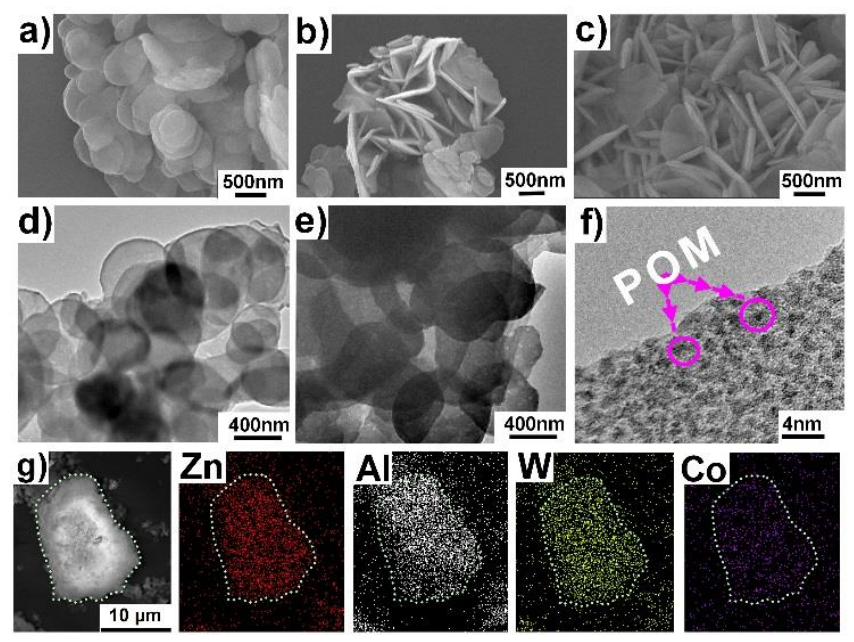

Figure 3. a-c) SEM images of $\mathrm{Zn}_{3} \mathrm{Al}-\mathrm{CoW}_{12}$; TEM images of d) $\mathrm{Zn}_{3} \mathrm{Al}-\mathrm{CoW}_{12}$ and e) $\mathrm{Mg}_{3} \mathrm{Al}-\mathrm{CoW}_{12}$; f) HRTEM image of $\mathrm{Zn}_{3} \mathrm{Al}-\mathrm{CoW}_{12}$; g) corresponding EDX mapping of the $\mathrm{Zn}_{3} \mathrm{Al}-\mathrm{CoW}_{12}$ composite.
According to the SEM and TEM images in Figure 3a-e, the irregular hexagonal disk-like LDHs crystallites are clearly observed for $\mathrm{Zn}_{3} \mathrm{Al}-\mathrm{CoW}_{12}$ with an average size of 300-500 nm. The obtained HRTEM image reveals the presence of highly dispersed black spots of $\sim 1 \mathrm{~nm}$ in diameter, which are in good agreement with the dimension of the $\mathrm{CoW}_{12}$ clusters (Figure 3f). Moreover, elemental mapping analyses (Figure $3 \mathrm{~g}$ ) reveal the uniform distribution of $\mathrm{Zn}, \mathrm{Al}, \mathrm{O}, \mathrm{W}$, Co, indicating that the $\mathrm{CoW}_{12}$ moiety is uniformly dispersed and incorporated in the intercalated composite, rather than a simple physical mixture with the $\mathrm{Zn}_{3} \mathrm{Al}-\mathrm{NO}_{3}$ precursor. The SEM and TEM analysis are also in agreement with the obtained FT-IR and XRD patterns.

The local environment of the $W$ and Co centers in the $\mathrm{Zn}_{3} \mathrm{Al}-\mathrm{CoW}_{12}$ has been further analyzed by $\mathrm{W}_{4 \mathrm{f}}$ and $\mathrm{Co}_{2 \mathrm{p}} \mathrm{XPS}$. As shown in Figure $4 a$, the XPS spectrum of $W_{4 f}$ photoemission consists of two peaks originating from the spin orbital splitting of the $W_{455 / 2}$ and $W_{447 / 2}$ at binding energy values of 37.2 and 35.15 $\mathrm{eV}$, respectively. For the bulk $\mathrm{K}_{5} \mathrm{CoW}_{12} \mathrm{O}_{40}$, the corresponding $W_{455 / 2}$ and $W_{447 / 2}$ located at binding energy values of 37.82 and $35.65 \mathrm{eV}$, respectively (Figure S3). This shift toward lower values is due to the presence of a series of intermolecular interactions (i.e. electrostatic and hydrogen bond networks 
developed between the hydroxyl groups in the brucite-like layers of $\mathrm{LDHs}$ and the terminal oxygen atoms of $\mathrm{CoW}_{12}$ anions). Moreover, the XPS of $\mathrm{Co}_{2 \mathrm{p}}$ region present two asymmetric main peaks centered at 774-791 and 791-810 eV, which correspond to $\mathrm{Co}_{2 \mathrm{p} 3 / 2}$ and $\mathrm{Co}_{2 \mathrm{p} 1 / 2}$ region, respectively. ${ }^{[29]}$ In the $\mathrm{Co}_{2 p 3 / 2}$ region, the intense peak located at $780.15 \mathrm{eV}$ and the absence of additional satellite peaks is ascribed to the signature of tetrahedral Co species in Keggin archetype (Figure 4b).

The Raman spectra of the $\mathrm{K}_{5} \mathrm{CoW}_{12} \mathrm{O}_{40}$ and $\mathrm{Zn}_{3} \mathrm{Al}-\mathrm{CoW}_{12}$ are presented in Figure 4c. It can be seen that the host of $\mathrm{Zn}_{3} \mathrm{Al}$ $\mathrm{LDHs}$ is not Raman active, allowing detection of all the W-O vibrations originating from the POM species. The characteristic peaks of bulk $\mathrm{K}_{5} \mathrm{CoW}_{12} \mathrm{O}_{40}$ are located at $981,883,785,571$, 233 and $161 \mathrm{~cm}^{-1}$, respectively, corresponding to the stretching vibration of $\mathrm{W}-\mathrm{O}_{d}, \mathrm{~W}-\mathrm{O}_{\mathrm{b}}$ and $\mathrm{Co}-\mathrm{O}$ bond, consistent with the $\mathrm{CoW}_{12}$ Keggin archetype. ${ }^{[30-31]}$ The above mentioned vibrations are also observed in the case of the $\mathrm{Zn}_{3} \mathrm{Al}-\mathrm{CoW}_{12}$ composite which are slightly red shifted to $966,771,559,231,159 \mathrm{~cm}^{-1}$, respectively. The observed Raman shifts are due to the strong electrostatic interactions and hydrogen bond networks between the brucite-like layers of LDHs and the intercalated $\mathrm{CoW}_{12}$ anions. Temperature-programmed desorption of ammonia $\left(\mathrm{NH}_{3-}\right.$ TPD) demonstrates that the $\mathrm{Zn}_{3} \mathrm{Al}-\mathrm{CoW}_{12}$ shows the $\mathrm{NH}_{3}$ desorption peak with a maximum at $362{ }^{\circ} \mathrm{C}$ in Figure $4 \mathrm{~d}$, which corresponds to the $\mathrm{NH}_{3}$ molecules adsorbed on strong acidic sites of the Keggin POM species.
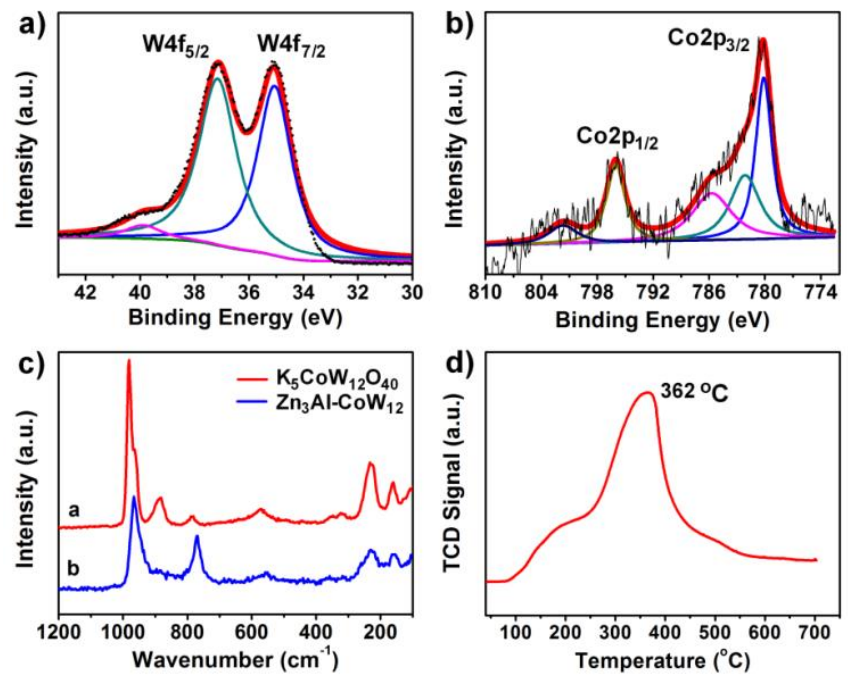

Figure 4. a) XPS spectra of $\mathrm{W}_{4 \mathrm{f}}$ of $\mathrm{Zn}_{3} \mathrm{Al}-\mathrm{CoW}_{12}$; b) Co2p of $\mathrm{Zn}_{3} \mathrm{Al}-\mathrm{CoW}_{12}$; c) Raman spectra of $\mathrm{K}_{5} \mathrm{CoW}_{12} \mathrm{O}_{40}$ and $\mathrm{Zn}_{3} \mathrm{Al}-\mathrm{CoW}_{12}$; d) The $\mathrm{NH}_{3}-\mathrm{TPD}$ curves of $\mathrm{Zn}_{3} \mathrm{Al}-\mathrm{CoW}_{12}$.

\section{Catalytic activity of $\mathrm{Zn}_{3} \mathrm{Al}-\mathrm{CoW}_{12}$ for aminolysis of epoxides}

The as-prepared $\mathrm{CoW}_{12}$ intercalated composites are studied as catalysts for aminolysis of epoxides with aniline, which yields two types of regio-isomers: $A$ and $B \quad \beta$-amino alcohol products where the selectivity for the A-isomer is always higher (Scheme 2).

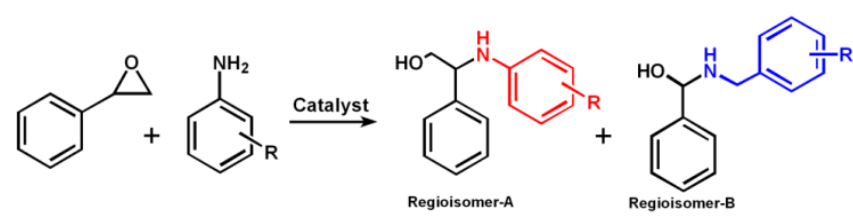

Scheme 2. The aminolysis of epoxides in the presence of $\mathrm{Zn}_{3} \mathrm{Al}-\mathrm{CoW} \mathrm{W}_{12}$

Table 2. Aminolysis of styrene oxide with aniline in the presence of POM based catalysts. ${ }^{[a]}$

\begin{tabular}{|c|c|c|c|c|}
\hline \multirow{2}{*}{ Entry } & \multirow{2}{*}{$\begin{array}{l}\text { Styrene oxide } \\
\text { Conversion (\%) }\end{array}$} & \multicolumn{2}{|c|}{$\beta$-Amino alcohol select. (\%) } & \multirow{2}{*}{$\begin{array}{c}\operatorname{TOF}^{[b]} \\
\left(h^{-1}\right)\end{array}$} \\
\hline & & A & B & \\
\hline None & - & - & - & - \\
\hline $\mathrm{K}_{5} \mathrm{CoW}_{12} \mathrm{O}_{40}$ & 96 & 92.9 & 7.1 & 51 \\
\hline $\mathrm{Na}_{3} \mathrm{PW}_{12} \mathrm{O}_{40}$ & 82 & 93.4 & 6.6 & 32 \\
\hline $\mathrm{K}_{4} \mathrm{SiW}_{12} \mathrm{O}_{40}$ & 68 & 93.0 & 7.0 & 28 \\
\hline $\mathrm{Mg}_{3} \mathrm{Al}-\mathrm{NO}_{3}$ & 6 & 99 & - & - \\
\hline $\mathrm{Zn}_{3} \mathrm{Al}-\mathrm{NO}_{3}$ & 8.0 & 99 & - & - \\
\hline $\mathrm{Mg}_{3} \mathrm{Al}-\mathrm{CoW}_{12}$ & 87 & 92.3 & 7.7 & 37 \\
\hline $\mathrm{Zn}_{3} \mathrm{Al}-\mathrm{CoW}_{12}$ & 92 & 93.1 & 6.9 & 45 \\
\hline
\end{tabular}

[a] Reaction conditions: $2 \mathrm{mmol}$ epoxide, $2 \mathrm{mmol}$ amine, $0.63 \mathrm{~mol} \%$ of catalyst , $\mathrm{T}=308 \mathrm{~K}$, reaction time $6 \mathrm{~h}$. [b] Based on the $\beta$-amino alcohol yield after $1 \mathrm{~h}$ and given in $\mathrm{mmol}$ of $\beta$-amino alcohol produced per $\mathrm{mmol}$ of catalyst per hour.

As shown in Table 2, under identical experimental conditions, the aminolysis of styrene oxide with aniline does not proceed in the absence of a catalyst while a small amount of aminolysis product $(<8 \%)$ is obtained in the presence of $\mathrm{Zn}_{3} / \mathrm{Mg}_{3} \mathrm{Al}-\mathrm{NO}_{3}$ as a catalyst. The $\mathrm{K}_{5} \mathrm{CoW}_{12} \mathrm{O}_{40}$ cluster demonstrated the higher catalytic activity, in comparison with the $\mathrm{Na}_{3} \mathrm{PW}_{12} \mathrm{O}_{40}$ and $\mathrm{K}_{4} \mathrm{SiW}_{12} \mathrm{O}_{40}$ with similar structure. These results reveal the superior performance of the $\mathrm{CoW}_{12}$ anions for the catalytic aminolysis of epoxides with aniline and subsequent formation of $\beta$-amino alcohol-based products. Notably, utilization of the $Z n_{3} \mathrm{Al}$ $\mathrm{CoW}_{12}$ as heterogeneous catalyst, exhibited good catalytic activity although seems that the diffusion and mass transfer have an influence on the activity of the heterogeneous reaction to some extent. This may be attributed to the regular porous structure of the intercalation material which induces enhanced accessibility and shorter diffusion pathways during the course of the catalytic reaction. ${ }^{[32-35]}$ The conducted control experiment, where $\mathrm{CoW}_{12}$ was incorporated in $\mathrm{Mg}_{3} \mathrm{Al}-\mathrm{NO}_{3}$, revealed an overall inferior performance demonstrating the existence of cooperative effects and the potential of fine tuning the properties of the composite material for a specific catalytic reaction. Based on the catalytic results discussed above, we can conclude that the $\mathrm{Zn}_{3} \mathrm{Al}-\mathrm{CoW}_{12}$ composite with uniform distributed catalytic active sites and regular ordered pore structure is one of the most efficient catalysts for the aminolysis of epoxides. For example, in the case of the model reaction carried out between styrene oxide and aniline, the intrinsic catalytic activity (turnover frequency [TOF]) of $\mathrm{Zn}_{3} \mathrm{Al}-\mathrm{CoW}_{12}$ found to be $45 \mathrm{~h}^{-1}$ in comparison with the reported ones for $\mathrm{Sc}(\mathrm{OTf})_{3}$, amberlyst-15 
and $\mathrm{NaY}$ catalysts with TOF values of $32,7,2$, and $0.8 \mathrm{~h}^{-1}$, respectively. ${ }^{[4]}$

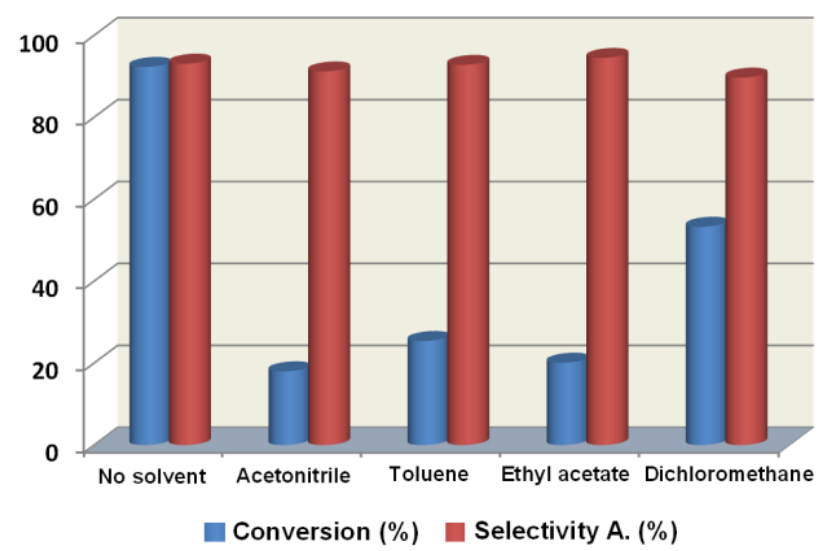

Figure 5. Figure Caption. Solvent effect on the aminolysis of styrene oxide. Reaction conditions: $2 \mathrm{mmol}$ styrene oxide, $2 \mathrm{mmol}$ aniline, $0.63 \mathrm{wt}$. \%, $5 \mathrm{ml}$ solvent or solvent-free, $308 \mathrm{~K}, 6 \mathrm{~h}$.

As shown in Figure 5, the investigation of the solvent effect on the catalytic aminolysis of styrene oxide with aniline shows that conversion of $18.0,25.4,20.1$ and $53.3 \%$ can be obtained in acetonitrile, toluene, ethyl acetate and dichloromethane, respectively. The conversion is higher in nonpolar solvents (such as dichloromethane) than in polar solvents (such as acetonitrile). Most importantly, the direct mixing of substrates under solventfree conditions exhibits a remarkable $92.3 \%$ conversion to the corresponding $\beta$-amino alcohol product. This indicates that the presence of solvents suppresses the catalytic efficacy. In an effort to confirm our hypothesis, solvent adsorption experiments were carried out using the composite catalyst under investigation (Table S1). We observed that the solvent molecules will compete with the substrate molecules for adsorption on the surface of the catalyst composite, especially in the polar solvent system, the solvent molecules interfere with the adsorption of the substrates on the catalyst. Thus, it is not surprising that the highest conversions were observed in the absence of solvent.

Figure $6 a$ illustrates the effect of the reaction time of styrene oxide conversion and corresponding product selectivity over $\mathrm{Zn}_{3} \mathrm{Al}-\mathrm{CoW}_{12}$ at $308 \mathrm{~K}$. At near-ambient conditions, it is observed that the corresponding isomer-A $\beta$-amino alcohol is the main product, and the conversion increased to $92 \%$ while the selectivity of isomer-A only slightly decreases to about $93 \%$ as a function of the reaction time. This may be due to the $2 \mathrm{D}$ rigid layered structure of the intercalated catalyst, which induces the formation of the smaller A-type regio-isomer and can be diffused easier in a confined space. In addition, as shown in Figure 7b, the elevated temperature has a notable effect on the catalytic activity but it only has a marginal effect on selectivity, since high reaction temperatures accelerate the ring-opening reaction.

As shown in Figure $6 \mathrm{c}-\mathrm{d}$, the kinetic parameters and apparent activation energies for the model reaction over $\mathrm{Zn}_{3} \mathrm{Al}-$ $\mathrm{CoW}_{12}$ have been determined by carrying out parallel experiments under different temperature regimes. " $\ln \left(C_{t} / C_{0}\right)$ " is plotted against reaction time, where " $C_{0}$ " and " $C_{t}$ " are the initial styrene oxide concentration and its corresponding concentration at time " $\mathrm{t}$ ", respectively. The linear fit of the data reveals that the reaction is first order with respect to styrene oxide. The apparent activation energy $\left(E \mathrm{a}=43.72 \mathrm{~kJ} \cdot \mathrm{mol}^{-1}\right)$ is calculated using the Arrhenius equation, $k=A \exp (-E \mathrm{a} / \mathrm{RT})$. The values of the kinetic rate constants at different temperature and apparent activation energy are listed in Table 3.
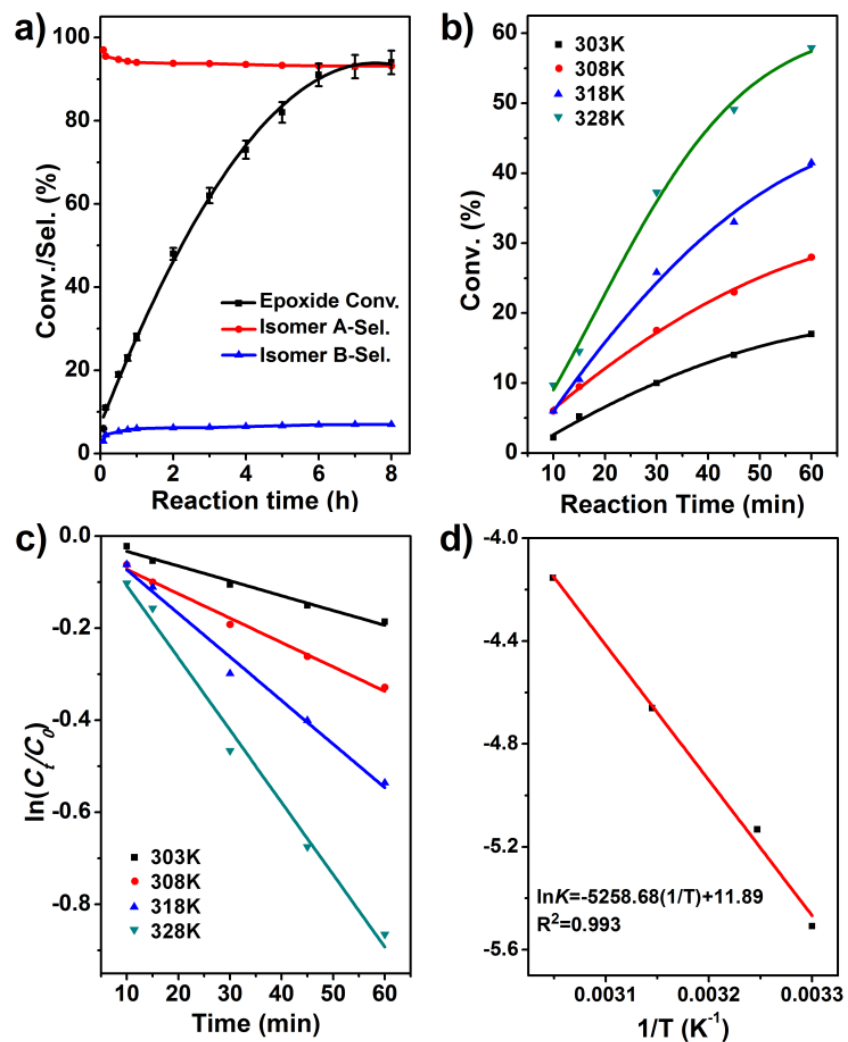

Figure 6. Aminolysis of styrene oxide. a) Effect of reaction time: reaction conditions $-2 \mathrm{mmol}$ styrene oxide, $2 \mathrm{mmol}$ aniline, $0.63 \mathrm{~mol} \% \mathrm{Zn}_{3} \mathrm{Al}-\mathrm{CoW}_{12}$, $\mathrm{T}=308 \mathrm{~K}$; b) Effect of temperature; c) Kinetic profiles under different temperature regimes; reaction conditions: $2 \mathrm{mmol}$ styrene oxide, $2 \mathrm{mmol}$ aniline, $0.63 \mathrm{~mol} \% \mathrm{ZnAl}-\mathrm{CoW}_{12}$; d) Arrhenius plots of the aminolysis of styrene oxide.

Table 3. Effect of temperature on the reaction of styrene oxide with aniline over $\mathrm{Zn}_{3} \mathrm{Al}-\mathrm{CoW}_{12}$.

\begin{tabular}{|c|c|c|c|c|c|c|}
\hline \multirow{2}{*}{$\underset{(\mathrm{K})}{\text { Temp }}$} & \multirow{2}{*}{$\begin{array}{l}\text { Epoxide } \\
\text { Conv. } \\
(\%)\end{array}$} & \multicolumn{2}{|c|}{ Product selec (\%) } & \multirow{2}{*}{$\begin{array}{l}\text { TOF } \\
\left(\mathrm{h}^{-1}\right)\end{array}$} & \multirow{2}{*}{$k\left(\min ^{-1}\right)^{[a]}$} & \multirow{2}{*}{$\begin{array}{l}(\mathrm{Ea})^{[\mathrm{b}]} \\
\left(\mathrm{kJ} \cdot \mathrm{mol}^{-1}\right)\end{array}$} \\
\hline & & $A$ & $B$ & & & \\
\hline 303 & 80.2 & 93.5 & 6.5 & 27 & $3.22 \times 10^{-3}$ & \\
\hline 308 & 92.4 & 93.1 & 6.9 & 45 & $5.29 \times 10^{-3}$ & 43.72 \\
\hline 318 & 94.5 & 92.6 & 7.4 & 58 & $9.46 \times 10^{-3}$ & \\
\hline 328 & 96.9 & 93.0 & 7.0 & 92 & $1.57 \times 10^{-2}$ & \\
\hline
\end{tabular}

[a] Rate constant. [b] Activation energy.

In an effort to explore the range of suitable substrates which can be converted by our catalytic system, we explored the aminolysis of a variety of epoxides catalyzed by the $\mathrm{Zn}_{3} \mathrm{Al}$ $\mathrm{CoW}_{12}$ composite (Table 4). It was observed that the ring 
opening of epoxides occurs with high regio-selectivity, and a series of $\beta$-amino alcohols can be obtained in moderate to high yields using a series of epoxides and amines. The reactivity depends on the structural features and intrinsic nature of the amines and epoxides used. In contrast to the aniline, substituted amines, such as 4-chloroaniline (entry 3 ), o-toluidine (entry 5), $\mathrm{m}$ - toluidine (entry 6), 4-ethylaniline (entry 7), 4-methoxyaniline (entry 8), led to the formation of the corresponding amino alcohols in lower yields. For the symmetrical epoxides, such as cyclohexene oxide, moderate conversion ( $48 \%$ ) of only transdiastereo isomer can be obtained at $308 \mathrm{~K}$. In addition, when the reaction temperature increased to $343 \mathrm{~K}$, the cyclohexene oxide conversion was rapidly increased to $96 \%$ while the selectivity remained unaffected (entry 10). It should be noted that, when aliphatic amines, such as $n$-butylamine, is used instead of aniline to react with styrene oxide, we observed the lowest yield of $\beta$-amino alcohol production (entry 11). Similar behaviour was observed in other reported catalytic systems, such as the titanosilicates, ${ }^{[36]}$ nanocrystalline $\mathrm{Zr}-\left.\mathrm{MF}\right|^{[37]}$ etc. Moreover, when the terminal epoxides, such as epichlorohydrin and propene oxide instead of styrene oxide were reacted with aniline, the corresponding regio-isomers A products were obtained at a conversion of 83 and $67 \%$, respectively (entry 12-13).

Table 4. Aminolysis of epoxides with amines over the $\mathrm{Zn}_{3} \mathrm{Al}-\mathrm{CoW}_{12}$

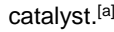

\begin{tabular}{|c|c|c|c|c|c|}
\hline Entry & Epoxide & Amine & $\begin{array}{l}\text { Epoxide } \\
\text { conv. (\%) }\end{array}$ & $\begin{array}{c}\text { Select. } \\
(\%)\end{array}$ & $\begin{array}{c}\text { TOF }^{[c]} \\
\left(h^{-1}\right)\end{array}$ \\
\hline 1 & & & 92 & 93.1 & 44.5 \\
\hline 2 & & & 95 & 97.2 & 55.6 \\
\hline 3 & & & 87 & 94.5 & 55.9 \\
\hline 4 & & & 92 & 87.0 & 41.3 \\
\hline 5 & & & 72 & 93.2 & 25.4 \\
\hline 6 & & & 80 & 91.0 & 33.4 \\
\hline 7 & & & 87 & 88.9 & 55.9 \\
\hline 8 & & & 71 & 80.6 & 25.1 \\
\hline 9 & & & 65 & 98.0 & 23.8 \\
\hline 10 & & & 48 & 99.9 & 20.6 \\
\hline $10^{[\mathrm{b}]}$ & & & 96 & 99.9 & 58.5 \\
\hline 11 & & & 5.2 & 27.4 & 3.7 \\
\hline 12 & & & 83 & 95.3 & 36.5 \\
\hline 13 & & & 67 & 87.8 & 24.2 \\
\hline
\end{tabular}

[a] Reaction conditions: $2 \mathrm{mmol}$ epoxide, $2 \mathrm{mmol}$ amine, $0.63 \mathrm{~mol} \%$ of $\mathrm{CoW}_{12}, \mathrm{~T}=308 \mathrm{~K}$, reaction time $6 \mathrm{~h}$. [b] $\mathrm{T}=343 \mathrm{~K}$. [c] The TOF was calculated based on the produced $\beta$-amino alcohol after $1 \mathrm{~h}$, and it is given in mmol of $\beta$-amino alcohol produced per hour per mmol of $\mathrm{CoW}_{12}$ present in the catalyst.

The observed difference is due to the basicity and the adsorption ability of the amines. As shown in Figure 7, there is a correlation between the rate of the reaction and the $p K a$ values of different amines. The rate of the reaction decreased when the basicity of the amine increased for most of the amine substrates.

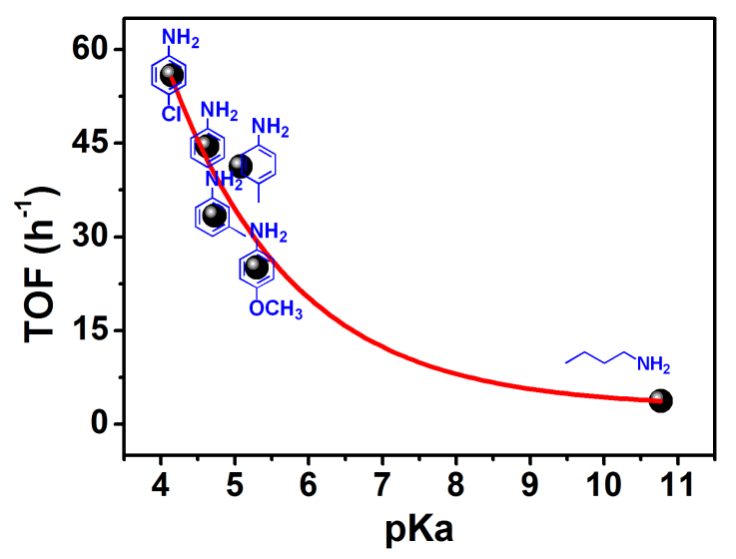

Figure 7. Correlation between the catalytic activity and the pKa values of the amines in the ring-opening aminolysis of styrene oxide. Reaction conditions: 2 $\mathrm{mmol}$ styrene oxide, $2 \mathrm{mmol}$ amine, $0.63 \mathrm{~mol} \% \mathrm{Zn}_{3} \mathrm{Al}-\mathrm{CoW}_{12}, \mathrm{~T}=308 \mathrm{~K}, \mathrm{t}=6$

In addition, the adsorption ability and effective diffusion towards the active sites is an essential prerequisite in the case of heterogeneous bimolecular reactions between the reactants..$^{[4,}$ 36] To confirm our hypothesis, we conducted a series of competitive adsorption experiments in the presence of our catalyst. Table 5 compares the relative adsorption of various epoxides and aniline based adducts and the corresponding TOFs. The epoxide/aniline adsorption ratios for styrene oxide (1.38) > epichlorohydrin $(0.91)>$ propene oxide $(0.86)>$ cyclohexene oxide $(0.75)$ were determined, while the rate of reaction decreased as a function of the decreased epoxide/aniline adsorption ratio. Thus, these findings elucidate the observed reactivity that decreases in the following order: styrene oxide $>$ epichlorohydrin $>$ propene oxide $>$ cyclohexene oxide in Table 5.

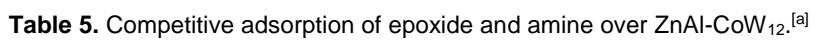

\begin{tabular}{|c|c|c|c|c|}
\hline \multirow{2}{*}{ Adsorbate substrate } & \multicolumn{2}{|c|}{$\begin{array}{l}\text { Amount adsorbed } \\
\text { (mmol/g catalyst) }\end{array}$} & \multirow{2}{*}{$\begin{array}{l}\text { adsorption ratio: } \\
\text { epoxide/amine }\end{array}$} & \multirow{2}{*}{$\begin{array}{l}\text { TOF } \\
\left(\mathrm{h}^{-1}\right)^{[\mathrm{b}]}\end{array}$} \\
\hline & Epoxide & Aniline & & \\
\hline Styrene oxide+aniline & 0.11 & 0.08 & 1.38 & 26.7 \\
\hline Epichlorohydrin+aniline & 0.10 & 0.11 & 0.91 & 21.9 \\
\hline Propene oxide+aniline & 0.07 & 0.08 & 0.86 & 14.5 \\
\hline $\begin{array}{l}\text { Cyclohexene oxide + } \\
\text { aniline }\end{array}$ & 0.06 & 0.08 & 0.75 & 12.4 \\
\hline
\end{tabular}

[a] $50 \mathrm{mg}$ of $\mathrm{Zn}_{3} \mathrm{Al}-\mathrm{CoW}_{12}$ was suspended for $1 \mathrm{~h}$ in equimolar amounts $(0.5$ mmol) of epoxide and amine dissolved in $5 \mathrm{~mL}$ of dichloromethane. The catalyst was, then, separated and the concentration of the substrate in the liquid portion was determined by gas chromatography. The amount adsorbed on the catalyst surface was determined by difference. [b] The TOF was calculated after $1 \mathrm{~h}$ of reaction and is based on the produced epoxide per $\mathrm{mmol}$ of $\mathrm{CoW}_{12}$ present in the catalyst per hour.

Heterogeneous nature of the catalytic system 

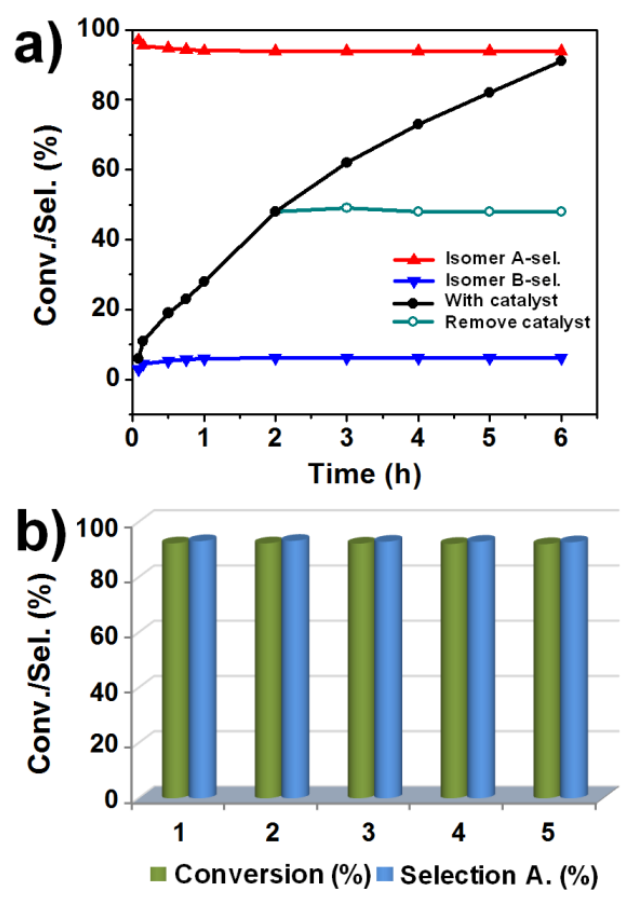

Figure 8. a) Effect of the $\mathrm{Zn}_{3} \mathrm{Al}-\mathrm{CoW}_{12}$ catalyst removal on the ring opening reaction of styrene oxide with aniline. b) Recycling test for the ring opening of styrene oxide with aniline over $\mathrm{Zn}_{3} \mathrm{Al}-\mathrm{CoW}_{12}$. Reaction conditions: $2 \mathrm{mmol}$ styrene oxide, $2 \mathrm{mmol}$ amine, $0.63 \mathrm{~mol} \% \mathrm{Zn}_{3} \mathrm{Al}-\mathrm{CoW}_{12}, \mathrm{~T}=308 \mathrm{~K}, \mathrm{t}=6 \mathrm{~h}$.

To verify whether the observed catalytic process is intrinsically heterogeneous, the $\mathrm{Zn}_{3} \mathrm{Al}-\mathrm{CoW}_{12}$ catalyst was removed by hot filtration when the conversion of styrene oxide was about $48 \%$, and then the reaction carried out using only the filtrate under the same experimental conditions (Figure 8a). Moreover, the inductively coupled plasma atomic emission spectroscopy (ICP-AES) analysis of the filtrate after the reaction verified the absence of tungsten or cobalt species in the filtrate (below the detection limit, W, Co: < $0.2 \%$ ). These results demonstrate that the observed catalytic system is truly heterogeneous while there is no detectable catalyst leaching in the catalytic reaction mixture. The $\mathrm{Zn}_{3} \mathrm{Al}-\mathrm{CoW}_{12}$ catalyst can be easily retrieved from the reaction mixture by simple centrifugation with > $95 \%$ recovery and reused at least five times without measurable loss of its catalytic performance (Figure 8b). Even at the fifth recycle test, we obtained $90 \%$ conversion of styrene oxide. The FT-IR, ${ }^{27} \mathrm{Al}$ MAS NMR spectra, SEM analyses of the $\mathrm{Zn}_{3} \mathrm{Al}-\mathrm{CoW}_{12}$ catalyst after the fifth catalytic cycle test suggest that the catalyst retain its morphology and structural integrity (Figure S4).

\section{Conclusions}

In summary, a robust and environmentally benign heterogeneous intercalation catalyst $\mathrm{Zn}_{3} \mathrm{Al}-\mathrm{CoW}_{12}$ was successfully prepared following a facile, time- and cost-effective one-step ion exchange method by incorporating $\mathrm{CoW}_{12}$ clusters into the $\mathrm{Zn}_{3} \mathrm{Al}-\mathrm{LDH}$ gallery. The resulting intercalation catalyst was fully characterized by various techniques. Aminolysis of various epoxides for the synthesis of a range of $\beta$-amino alcohols with high regio- and stereo-selectivity using the $\mathrm{Zn}_{3} \mathrm{Al}$ $\mathrm{CoW}_{12}$ composite as catalyst was demonstrated under mild and most importantly, solvent-free conditions. Detailed investigation of the catalytic system revealed that the conversion rates in terms of observed TOF numbers and selectivity of the catalysis products were directly correlated with the basicity of the aminebased substrates as well as the absorption and diffusion of the epoxides. Thus, considering the modularity of the system and the ability to modify the acidity of the composites' components, the catalytic system could be finely tuned for a specific aminolysis reaction. Additionally, the intercalation catalyst can be easily separated, recycled and reused at least five times without any significant loss of catalytic activity and selectivity. The easy preparation, simple work-up procedures and the modularity of the robust heterogeneous acid intercalation catalyst $\mathrm{Zn}_{3} \mathrm{Al}-\mathrm{CoW}_{12}$ in the ring opening reactions shows great promise for applications in industrial manufacturing of high value-added fine chemicals.

\section{Experimental Section}

Chemical materials: Styrene oxide, cyclohexene oxide, propylene oxide, epichlorohydrin, aniline, 4-bromoaniline, 4-chloroaniline, 4-methylaniline, o-toluidine, m-toluidine, 4-ethylaniline, 4-methoxyaniline, 3methylpiperidine, $\quad \mathrm{Na}_{2} \mathrm{WO}_{4} \cdot 2 \mathrm{H}_{2} \mathrm{O}$, acetic acid, $\mathrm{CoAc}_{2} \cdot 4 \mathrm{H}_{2} \mathrm{O}$, $\mathrm{Mg}\left(\mathrm{NO}_{3}\right)_{2} \cdot 6 \mathrm{H}_{2} \mathrm{O}, \mathrm{Zn}\left(\mathrm{NO}_{3}\right)_{2} \cdot 6 \mathrm{H}_{2} \mathrm{O}, \mathrm{NaOH}, \mathrm{K}_{2} \mathrm{~S}_{2} \mathrm{O}_{8}, \mathrm{KCl}$, ethanol and ether were purchased from Sigma Aldrich. The starting materials were used as received without any further purification. $\mathrm{Zn}_{3} \mathrm{Al}-\mathrm{NO}_{3},{ }^{\left[{ }^{22}\right]} \mathrm{Mg}_{3} \mathrm{Al}-\mathrm{NO}_{3},{ }^{[22]}$ $\mathrm{K}_{5} \mathrm{CoW}_{12} \mathrm{O}_{40} \cdot 14 \mathrm{H}_{2} \mathrm{O}\left(\mathrm{CoW}_{12}\right)^{[38]}$ were synthesized according to previously reported procedures.

Instruments: Fourier transform infrared (FT-IR) spectra were recorded on a Bruker Vector 22 infrared spectrometer using the $\mathrm{KBr}$ pellet method. Powder X-ray diffraction (XRD) analysis was performed on a Bruker D8 diffractometer using high-intensity $\mathrm{Cu}$-Ka radiation $(\lambda=0.154 \mathrm{~nm})$. The solid-state ${ }^{27} \mathrm{Al}$ MAS NMR experiment was carried out on a Bruker Ascend Aeon 400 WB solid-state spectrometer equipped with a commercial $4 \mathrm{~mm}$ MAS NMR probhd. Thermogravimetric (TG) analysis was performed on a STA-449C Jupiter (HCT-2 Corporation) at a heating rate of $10^{\circ} \mathrm{C}$ min-1 from 25 to $900^{\circ} \mathrm{C}$ under $\mathrm{N}_{2}(20 \mathrm{~mL} / \mathrm{min})$. Inductively coupled plasma-atomic emission spectroscopy (ICP-AES) analysis was performed on a Shimadzu ICPS-7500. BET measurements were performed at $77 \mathrm{~K}$ on a Quantachrome Autosorb-1C analyzer. $\mathrm{N}_{2}$ adsorption-desorption isotherms were measured using a Quantachrome Autosorb-1 system at liquid nitrogen temperature. Scanning electron microscopy (SEM) images and energy dispersive X-ray spectroscopy analytical data (EDX-Mapping) were obtained using a Zeiss Supra 55 SEM equipped with an EDS detector. High resolution Transmission Electron Microscopy (HRTEM) was conducted on JEOL JEM-2100 under an accelerating voltage of $400 \mathrm{kV}$. X-ray photoelectron spectroscopy (XPS) measurements were performed using a monochromatized Al K exciting X-radiation (PHI Quantera SXM). Raman spectra were measured on a Renishaw Raman spectrometer using a laser excitation wavelength of $532 \mathrm{~nm}$. The acidity of the composites were probed by the temperature-programmed desorption of ammonia ( $\mathrm{NH}_{3}$-TPD) using a PCA-1200 Chemical adsorption apparatus. The sample $(70 \mathrm{mg})$ was degassed by heating at $200{ }^{\circ} \mathrm{C}$ for 30 min under a Ar stream $30 \mathrm{~mL} \mathrm{~min}^{-1}$ and then treated with $\mathrm{NH}_{3}$ stream $\left(30 \mathrm{~mL} \mathrm{~min}^{-1}\right)$ at $100{ }^{\circ} \mathrm{C}$ for $30 \mathrm{~min}$. 
Physically adsorbed $\mathrm{NH}_{3}$ was removed using Ar stream at $100{ }^{\circ} \mathrm{C}$ for 10 min. Chemisorbed $\mathrm{NH}_{3}$ was desorbed by heating from about $30^{\circ} \mathrm{C}$ up to $700{ }^{\circ} \mathrm{C}$ at a rate of $10^{\circ} \mathrm{C} \mathrm{min}^{-1}$.

Synthesis of LDHs-POM catalysts: The $\mathrm{Zn}_{3} \mathrm{Al}-\mathrm{CoW}_{12}$ and $\mathrm{Mg}_{3} \mathrm{Al}-$ $\mathrm{CoW}_{12}$ were synthesized according to the literature method. ${ }^{[39]}$ Deionized and decarbonated water was used to prepare the corresponding aqueous solution.

The intercalation of $\left[\mathrm{CoW}_{12} \mathrm{O}_{40}\right]^{5-}$ into $\mathrm{LDHs}$ was carried out by adding one-fold excess of POM solution to freshly prepared $\mathrm{Zn}_{3} \mathrm{Al}-\mathrm{NO}_{3}$ slurry via an ion exchange process. Typically, the freshly prepared $\mathrm{Zn}_{3} \mathrm{Al}_{-} \mathrm{NO}_{3}$ (5 $\mathrm{mmol}$ ) was dispersed in $100 \mathrm{ml}$ aqueous solution under $\mathrm{N}_{2}$. Then, the $\left[\mathrm{CoW}_{12} \mathrm{O}_{40}\right]^{5-}(0.02 \mathrm{M}, 100 \mathrm{ml})$ was added dropwise to the above $\mathrm{Zn}_{3} \mathrm{Al}$ $\mathrm{NO}_{3}$ slurry (under $\mathrm{N}_{2}$ ) and stirred for $3 \mathrm{~h}$ at $90^{\circ} \mathrm{C}$ under inert atmosphere. The pale-yellow solid of $\mathrm{Zn}_{3} \mathrm{Al}-\mathrm{CoW}_{12}$ obtained after centrifugation was washed with boiling water $(3 \times 20 \mathrm{~mL})$ and dried at room temperature under vacuum. Synthesis of $\mathrm{Mg}_{3} \mathrm{Al}-\mathrm{CoW}_{12}$ was similar to the $\mathrm{Zn}_{3} \mathrm{Al}$ $\mathrm{CoW}_{12}$ analogue.

Aminolysis of epoxides: The catalytic investigations for synthesis of $\beta$ amino alcohols were performed in $10 \mathrm{ml}$ round-bottle glass flask with a cryogenic liquid condenser under atmospheric pressure. The epoxide (2 $\mathrm{mmol})$, equimolar quantity of amine $(2 \mathrm{mmol})$ and catalyst $(0.63 \mathrm{~mol} \%$, $\mathrm{Zn}_{3} \mathrm{Al}-\mathrm{CoW}_{12}$ contained $6.3 \mu \mathrm{mol}$ of $\left[\mathrm{CoW}_{12} \mathrm{O}_{40}\right]^{5-}$ species) were mixed in a $20 \mathrm{ml}$ reaction vessel under vigorous stirring. The reaction was conducted at $308 \mathrm{~K}$ for a specific period of time. The reaction was monitored by taking out aliquots of the reaction mixture at specific time intervals, diluting them with a known quantity of diethyl ether, separating the catalyst and injecting the diluted liquids to a Shimadzu GC-2010 Detector-Mass spectrometer (GC-MS-QP2010S), fitted with AOC-20i Auto Injector and ZB-5MS column (30 $\mathrm{m} \times 0.25 \mathrm{~mm} \times 0.25 \mu \mathrm{m})$. The column oven and injection temperature were set at 60 and $250{ }^{\circ} \mathrm{C}$, respectively. The column temperature was increased from 60 to $260{ }^{\circ} \mathrm{C}$ using a ramp rate of $15^{\circ} \mathrm{C} / \mathrm{min}$ and held at $260^{\circ} \mathrm{C}$ for $4 \mathrm{~min}$. The GC peaks were identified by comparing the obtained retention times with known standard solutions using a Shimadzu GC-MS QP2010S equipped with GC-MS detector. The products were also purified using column chromatography (eluent: petroleum ether-ethyl acetate mixture) and characterized by ${ }^{1} \mathrm{H}$ NMR and ${ }^{13} \mathrm{C}$ NMR studies.

\section{Acknowledgements}

This research was supported by the National Key Research and Development Program of China (2017YFB0307303), the National Nature Science Foundation of China, the 973 program (Grant No. 2014CB932104), Beijing Natural Science Foundation (2182047) and the Fundamental Research Funds for the Central Universities (XK1530, XS1601, ZY1709). H. N. M. acknowledges the financial support from the University of Glasgow.

Keywords: intercalation catalyst • layered double hydroxides • polyoxometalates $\cdot$ ring opening reaction

\section{References}

[1] E. J. Corey, F. Y. Zhang, Angew. Chem., Int. Ed., 1999, 38, 1931-1934.

[2] D. J. Ager, I. Prakash, D.R. Schaad, Chem. Rev. 1996, 96, 835-876.

[3] T. Baskaran, A. Joshi, G. Kamalakar, A. Sakthivel, Appl Catal A: Gen, 2016, 524, 50-55.

[4] L. Saikia, J.K. Satyarthi, D. Srinivas, P. Ratnasamy, J. Catal, 2007, 252, 148-160.

[5] P. O’Brien, Angew. Chem., Int. Ed., 1999, 38, 326-329.

[6] R.M. Hanson, Chem. Rev. 1991, 9, 437-475.

[7] J. Igbal, A. Pandey, Tetrahedron Lett. 1990, 31, 575-576.

[8] S. Chandrasekhar, T. Ramachandar, S. J. Prakash, Synthesis, 2000 13, 1817-1818.

[9] L.R. Reddy, M.A. Reddy, N. Bhanumathi, K.R.Rao, Synthesis, 2001, 6, 831-832.

[10] P. V de Weghe, J. Collin, Tetrahedron Lett. 1995, 36, 1649-1652.

[11] S. Sagava, H. Abe, Y. Hase, T. Inabe, J. Org. Chem. 1999, 64, 4962 4965

[12] G. Sekar, V. K. Sing, J. Org. Chem. 1999, 64, 287-289.

[13] J. Yamada, Y. Yumoto, Y. Yamamoto, Tetrahedron Lett. 1989, 30 4255-4258.

[14] M. Vijender, P. Kishore, P. Narender, B. Satyanarayana, J. Mol. Catal A: Chem. 2007, 266, 290-293.

[15] R. Garcia, M. Martinez, J. Aracil, Chem. Eng. Technol. 1999, 22, 987 990.

[16] T. F. Li, W. Zhang, W. Chen, H. N. Miras, Y-F. Song, ChemCatChem 2018, 10, 188-197.

[17] H. N. Miras, L. Vilà-Nadal, L. Cronin, Chem. Soc. Rev. 2014, 43, 5679 5699

[18] Y. Zhou, G. Q. Chen, Z. Y. Long, J. Wang, RSC Adv. 2014, 4, 42092 42113.

[19] C. Chen, H. Y. Yuan, H. F. Wang, Y. F. Yao, W. B. Ma, J. Z. Chen, Z. S Hou, ACS Catal. 2016, 6, 3354-3364.

[20] S. S. Wang, G. Y. Yang, Chem. Rev. 2015, 115, 4893-4962.

[21] M. Lechner, R. Güttel, C. Streb, Dalton Trans., 2016, 45, 16716-16726.

[22] S. Zhao, J. H. Xu, M. Wei, Y-F. Song, Green Chem., 2011, 13, 384-389.

[23] S. Omwoma, W. Chen, R. Tsunashima, Y-F. Song, Coord Chem Rev. 2014, 258-259, 58-71.

[24] A. L. Nolan, C. C. Allen, R. C. Burns, D. C. Craig, G. A. Lawrance, Aust. J. Chem., 2000, 53, 59-66.

[25] T. F. Li, Z. L. Wang, W. Chen, H. N. Miras, Y-F. Song, Chem. Eur. J. 2017, 23, 1069-1077.

[26] Y. Y. Liu, K. Murata, T. Hanaoka, M. Inaba, K. Sakanishi, J. Catal, 2007 248, 277-287.

[27] M. R. Weir, R. A. Kydd, Inorg. Chem. 1998, 37, 5619-5624

[28] A. Y. Park, H. Kwon, A. J. Woo, S. J. Kim, Adv. Mater. 2005, 17, 106109.

[29] R. F. Xie, G. L. Fan, L. Yang, F. Li, Chem Eng J. 2016, 288, 169-178.

[30] E. I. Ross-Medgaarden, I. E. Wachs, J. Phys. Chem. C, 2007, 111, 15089-15099.

[31] M. Li, M. Zhang, A.M. Wei, W.S. Zhu, S.H. Xun, Y. N. Li, H. P. Li , H. M Li, J Mol Catal A-Chem, 2015, 406, 23-30.

[32] B. Tang, W.L. Dai, X.M. Sun, G.J. Wu, N.J. Guan, M. Hunger, L.D. Li, Green Chem., 2015, 17, 1744-1755.

[33] J. Pérez-Ramírez, C. H. Christensen, K. Egeblad, C. H. Christensen,J. C. Groen, Chem. Soc. Rev., 2008, 37, 2530-2542.

[34] R. Chal, C. Gerardin, M. Bulut, S. van Donk, ChemCatChem, 2011, 3, 67-81.

[35] S. Lopez-Orozco, A. Inayat, A. Schwab, T. Selvam, W. Schwieger, Adv. Mater., 2011, 23, 2602-2615.

[36] A. Kumar, D. Srinivas, J. Catal., 2012, 293, 126-140

[37] R. Kore, R. Srivastava and B. Satpati, ACS Catal., 2013, 3, 2891-2904.

[38] E. Rafiee, A. Azad, Synthetic Commun, 2007, 37, 1127-1132.

[39] P. Liu, C. H. Wang, C. Li, J. Catal., 2009, 262,159-168. 


\section{FULL PAPER}

In recent years, great attention has been dedicated to the development of novel solid acid intercalation catalysts owing to their facile preparation and modular inter-lamellar chemical environment. Herein, we demonstrate for the first time the use of $\left[\mathrm{CoW}_{12} \mathrm{O}_{40}\right]^{5}$ intercalated layered double hydroxides $\left(\mathrm{Zn}_{3} \mathrm{Al}-\mathrm{LDH}\right)$ material as an efficient solid acid catalyst for the aminolysis of various epoxides under mild and solvent-free conditions. Catalytic performance of the resulting intercalation catalyst for the aminolysis of epoxides revealed excellent yields, high regioselectivity and stereoselectivity.
Tengfei Li, ${ }^{\text {at }}$ Lin Jin, ${ }^{\text {at }}$ Wei Zhang, ${ }^{\text {a }}$ Haralampos N. Miras ${ }^{* b}$ and Yu-Fei Song *ac

Page No. - Page No.

Robust and environmentally benign solid acid intercalation catalysts for the aminolysis of epoxides 